\title{
Introducing Adaptivity Features to a Regular Learning Management System to Support Creation of Advanced eLessons
}

\author{
Zivana KOMLENOV, Zoran BUDIMAC, Mirjana IVANOVIC \\ Faculty of Science, Department of Mathematics and Informatics, University of Novi Sad \\ Trg Dositeja Obradovica 4, 21000 Novi Sad, Serbia \\ e-mail: \{komlenov, zjb, mira\}@dmi.uns.ac.rs
}

Received: October 2009

\begin{abstract}
In order to improve the learning process for students with different pre-knowledge, personal characteristics and preferred learning styles, a certain degree of adaptability must be introduced to online courses. In learning environments that support such kind of functionalities students can explicitly choose different paths through course contents or can be directed to different parts of the instructional material depending on the pace of their advancement in acquiring new knowledge. This paper presents the implementation of such an environment by extending open source learning management system Moodle.
\end{abstract}

Keywords: course management system, learning preferences, student-centred approach, personalization.

\section{Introduction}

Contemporary instructional design focuses on providing diverse means of supporting learning in a more personalized, flexible, portable, and on-demand manner. Offerings by universities can thus be envisioned as providing educational content that can be organized and modified in numerous ways to address the requirements of the widely varied groups that want to participate in eLearning (Bothe et al., 2009). A vast segment of the eLearning industry is becoming devoted to such tailoring and repurposing (Bergsträßer et al., 2007). Even more challenging task nowadays is to fulfil the rising need to adapt eLearning to each particular individual approaching a course online.

During the last decade diverse practical approaches have been used to implement contemporary software solutions based on the established theoretical postulates, trends in cognitive science, artificial intelligence, and pedagogy applied in the field nowadays known as eLearning. Several years ago Learning Management System (LMS) approach was chosen as basis for a reliable eLearning platform that would comply with emerging standards and best practices recommended by respectable stakeholders in the growing eLearning market (Georgouli et al., 2008).

This sort of solutions has since been used at our Department as well, mainly for design and implementation of blended courses that are used to support classroom train- 
ing (Budimac et al., 2009). The developed eCourses, in fact learning objects at the 3rd aggregation level according to IEEE Learning Object Metadata (LOM) standard (IEEE P1484.12.1-2002, 2002), contain a variety of resources and activities (quizzes, glossaries, assignments, etc.), but their core content is presented within rather complex eLessons.

An eLesson presents a learning object at the 2nd aggregation level according to LOM standard (IEEE P1484.12.1-2002, 2002). In fact it presents a collection of level 1 learning objects (e.g., raw media data or fragments) connected to each other. Each of these atomic learning objects at the smallest level of aggregation contains an optimal amount of information which a student should accept during the presentation. eLessons, used as the basic form of delivering learning material to students, can further be presented in a linear or a non-linear fashion. Such electronic lectures have been proven to be the most effective way of ensuring that content is communicated clearly, especially if topics presented are new and complex (Driscoll and Carliner, 2005).

Although they basically present equivalents to face-to-face lectures, eLessons can offer additional resources, richness of multimedia applied, as well as possibility for students to take as much time as they need to explore their content and find ways to use it in various assignments and future work.

Certain degree of adaptability has therefore been introduced to our eLessons, so that students can explicitly choose different paths through eLessons or can be directed to different parts of the instructional material depending on their answers to the encountered questions. As essential LMS features needed for construction of personalized learning scenarios, the following are required (Komlenov et al., 2008):

- advanced branching,

- interconnections between learning objects inside an eLesson,

- possibilities to reuse some parts of eLessons by connecting them vertically,

- pre-/post-test facilities and accompanying sequencing abilities with or without remediation.

Given that thorough analysis of the LMS market showed that there was no system with all necessary features, we decided to try to find the best solution in our circumstances. It had to be a specially designed LMS or a modification of an existing one by adding personalization features. The second approach was chosen in order to avoid implementing basic features from scratch and to focus on developing supplementary navigational possibilities for an already reliable platform.

The rest of the paper is organized as follows. Section 2 presents current trends in design and implementation of adaptive hypermedia systems for learning purposes. In Section 3, methods and tools for personalized data (re)presentation are discussed. Section 4 offers rationale for choosing open source learning management system Moodle as the most suitable for improvements towards adaptivity. Its recently developed navigational extensions are explored in the same section. Finally, some conclusions are presented in Section 5. 


\section{Related Work}

Designers of eCourses often make a reasonable decision to use an existing eLearning platform (Ahmed, 2005) for developing their eCourses instead of developing a new one from scratch. The authors have therefore tested several systems, consulted a number of comparative studies and research papers such as (Graf and List, 2005; Munoz and Van Duzer, 2005; Di Domenico et al., 2005; Tiarnaigh, 2005; Hauger and Köck, 2007; Stewart et al., 2007; Portela Núñez et al., 2009) and drawn some conclusions on available tools.

Some efforts towards the personalisation of the learning experience, have already been made (Di Domenico et al., 2005; Hauger and Köck, 2007; Kostolányová et al., 2009). It is usually introduced either by providing the possibility to define groups of users to which different learning paths/activities are presented, or by releasing learning components for student consumption only when certain sets of rules are satisfied.

There are even some tools, like PaKMaS (Süß et al., 2000), that are able to automatically build learning paths using the available educational material. Moreover, students themselves can annotate the learning material and construct their personal learning paths. Some of the systems are addressing the issues of multi-learner personalization, but systems like for instance AHA! (De Bra et al., 2003), ELM-ART (Weber and Brusilovsky, 2001), APeLS (Hockemeyer et al., 2003), AVANTI (Fink et al., 1997), INSPIRE (Grigoriadou et al., 2001), AHyCo (Hoic-Bozic and Mornar, 2005), which offer advanced adaptivity often support only few functions of Web-enhanced education, and the content of courses is not available for reuse. Therefore, the acceptance of such systems is not very high.

Consequently, making the decision on which solution should be used was not too difficult. Naturally, it had to be one of the established general purpose LMSs, preferably an open source one (Ahmed, 2005). Apart from considerable initial cost savings, flexibility and availability of additional features in open source software offers extra functionality in comparison to proprietary software. Evaluation of open source LMSs was based on the qualitative weight and sum approach, as suggested in Graf and List (2005), with special focus on adaptation issues:

- adaptability - facilities to customize the platform for the educational institution's needs;

- personalization - features that allow individual users to customize their view of the platform;

- extensibility - measure of the ability of the system to be extended and the level of effort required to implement the extensions;

- adaptivity capabilities - automatic adaptation to the individual user's needs.

Adaptivity features were found to be underdeveloped in the majority of platforms. Since there was no LMS with all the needed possibilities and ways to realize specific learning paths our eCourses needed, the most satisfactory solution had to be chosen for initial use and improvement. Final choice was Moodle (Rice, 2006), for its fine basic features and great extensibility potential. In addition, this solution has been in use at our Department for several years now to the great satisfaction of both students and teach- 
ing staff (Bothe et al., 2009). Its latest features and increasing popularity at universities worldwide, only confirmed our choice.

Our attempt to build up this LMS towards a more adaptive platform is not the only one conducted so far. There were several other endeavours to introduce either adaptation on content level or the link level into Moodle, depending on whether the researchers wished to support adaptive presentation or simply to introduce adaptive navigation. Also, adaptivity can be provided based on different characteristics of students. For instance, a system can incorporate the prior knowledge, the learning goals, the cognitive abilities, and the learning styles of students.

Exactly this last concept for providing adaptivity in LMS based on learning styles was introduced in Moodle at the Vienna University of Technology (Graf, 2007). They use the Felder-Silverman learning style model (FSLSM), one of the most often used models in adaptive educational systems in recent times. A course structure consisting of several chapters is assumed. For presenting the content of the course, content objects are considered - actually pages that include the relevant learning materials. The adaptation features include the sequence of examples, exercises, and self-assessment tests and determine whether they are presented before the content objects, after the content objects or at both positions. Another adaptation feature is the number of presented examples and exercises.

The intelligent Learning-Management-System (iLMS), on the other hand, is a prototype of a navigation-based learner-adaptive e-learning-system created in at Technical University Ilmenau (Sauerstein, 2007). It was implemented as an additional course format and some modular blocks for Moodle. iLMS plug-in uses case-based reasoning to calculate the necessary adaptations which are displayed by adaptive annotation symbols. Cases are learned automatically by the system during the learning process of each student.

The approach we took was to match the individual instructions (in our courses eLessons) to the abilities of students and teach according to the students' strengths, i.e., to make learning as painless and as efficient as possible. This means that we had to provide conditional presentation, but also to support adaptive navigation by exploring and extending the existing Lesson module of Moodle. As the user's possible answers on a question can be used as starting points for different learning paths, some kind of "weak adaptivity" is supported by default. However, we made the Lesson module much more adaptive in order to improve reusability of learning material and make this feature more flexible for both teachers and students. Possibilities to directly connect contents of different assets and vertically bond learning objects (LOs) from different contexts were introduced. Further help for teachers is the ability of the system to trace students' advancement and modify their learning paths automatically. In addition, it is possible to engage students in pre-test $=>$ study $=>$ post-test structured activities, thanks to the modules sequencing capabilities we have recently developed. All these extensions can be used to enable students to progress through eLessons along paths determined by the designer or their own choices. 


\section{Personalized Instructional Data (Re)presentation - Our Prior Experiences}

Different approaches and shells for information representation (storing) and presentation (displaying) have been developed at our Department in consideration of their possible application in authoring, i.e., CAI or intelligent tutoring systems (Budimac and Ivanovic, 1992; Ivanovic and Budimac, 1992).

Basic structure of our educational systems is built upon the following educational philosophy. Every lesson can be divided in smaller, relatively independent parts, basically aggregation level 1 learning objects according to LOM standard (IEEE P1484.12.1-2002, 2002). We consider them to be basic learning objects and use this term to relate to them, as well as the abbreviation LO. They are interconnected into a semantic entirety that can be envisioned in a form of a multi-digraph. Such structure is in fact a graph with oriented edges only. Multiple edges between two nodes are allowed. LOs, as graph nodes, store multimedial information, while graph edges present the possible educational paths through the multi-digraph.

The presentation consists of movements from LO to LO in specified way and displaying information contained in each one of them. Various paths through multi-digraph can be predetermined by instructional designer or more or less freely chosen:

- after every LO reviewed student can pick the next one to be seen from a pool of available LOs offered as possible logical continuations of the learning path;

- the instruction is gradually formed according to the students' pre-knowledge and their answers to questions prompted during the presentation.

The students should form their own learning paths by exploring the contents gradually presented to them. In order to track the level of user acceptance of the learning material presented, CAI systems prompt different types of questions at every stage of presentation. Depending on the correctness of user answers there are several possibilities of learning path continuation:

- if the student answers correctly to the posed question, and there are more unanswered questions in the same LO, the learning path can be continued towards one of those;

- if the student answers correctly to the posed question, and that is the last question in the current LO, the learning path is continued by navigating to another LO;

- if the student gives a wrong answer to the posed question, the learning path can be directed to additional explanation or an already presented LO, in order to revise that part of the lesson (some early forms of scaffolding teaching);

- if the student answers correctly to the posed question, and that is the last question in the last LO, the learning path should end.

Also there is possibility for students who score very well on certain tests to skip some LOs they are already familiar with, and therefore end their learning paths in faster and easier way. Different paths through the learning material enable accepting information with or without solving tasks, with more or less repeating, with or without additional explanations and so on (Ivanovic and Budimac, 1992). 
Based on the described structure OSOF, an educational software tool intended for CAI, was implemented at our Department in early '90s. OSOF enabled process of creating and using eLessons and testing the acquired knowledge. It consisted of three basic modules for the main activities organized around such structure:

- TEA - subsystem used for online, non-automatic and non-intelligent creation of educational sequence, input of all necessary knowledge for each notion and for creation of lesson structure and relations between notions, i.e., teaching;

- LEA - subsystem used for learning using eLessons created with TEA;

- EXA - subsystem used for testing knowledge acquired by using LEA.

Further research in this field conducted at the Department was based on objectoriented paradigm and usage of a specialized programming language Less. Less was suitable for description and implementation of a wide range of information management systems (Budimac and Ivanovic, 1992). As a simple programming language based on recognized primitive data types and primitive data classes, alongside concepts of inheritance and embedding, Less was used as a mechanism for defining authoring systems.

In that period the tools developed at our Department were successfully applied in several schools and faculties. Superb concepts applied in their design, well implemented functionalities and extremely accessible organization of these tools, as well as the overall satisfaction of both students and teachers were key motivational factors for further exploration and reimplementation of the most effective features they offered using contemporary technologies.

\section{Navigational Extensions of the Chosen eLearning Platform}

Based on previous discussion Moodle can be seen as the best currently available platform concerning extensibility and adaptation issues. The advantages of this platform are extensively exploited in courses developed at our Department, especially those built within DAAD (SE-CSERC, 2009) and Tempus (JMCSE, 2007) supported projects.

$e$ Content offered by a certain educational institution like ours, presenting the complete electronic learning material used to support traditional lectures and lab exercises, can practically be regarded as a set of learning objects at the 4th, largest level of granularity according to LOM standard (IEEE P1484.12.1-2002, 2002), i.e., collections of eCourses (level 3 learning objects) that lead to certain certificates. They are structured more or less according to face-to-face courses and contain various resources and activities. Nevertheless, main content is presented in rather complex eLessons.

eLessons, as level 2 learning objects, are usually designed to serve as self-paced instruction. Thus they should be developed as sophisticated learning activities that use branching strategies based on pre-test scores, student's preferences, and assessment assets scattered throughout them. Such an effort put into design of eLessons would directly influence producing new students' knowledge through personalized learning experience. Nevertheless, proper tools are required for such endeavours.

Moodle provides a powerful, potentially adaptive module called Lesson, used to present a topic in a lecture-like form. The topic is broken into small parts and shown 
to the student bit by bit. Within such an eLesson these parts are called pages. These pages, or shorts sequences of them that cover meaningful segments of the lesson, are here regarded as basic learning objects (LOs).

A series of pages forming an eLesson can be presented in a linear fashion, like a slide show, in a non-linear, branching manner, or a combination of the two. eLessons can be graded using questions, or used simply for studying and practice. Students can be routed automatically through pages depending on the answer to a question posed after some of the pages.

The authors' recent efforts on extending Moodle's Lesson module resulted in eLessons now having useful ability to reference parts of other eLessons within the course. Apart from that, the extensions allow transitions from one LO to the other which are applied after the automatic analysis of student's previous activity (Komlenov et al., 2008). In accordance to that, basic $\mathrm{LO}$ can be seen as a hypertext asset with following possible features (Fig. 1):

- already existing features:

? - HTML asset containing a question,

S - returning back to the same asset, probably after the wrong answer;

- newly developed or extensively modified features:

$\longrightarrow$ - continuance of the learning path towards another asset within the course, depending on the answer (an existing feature was modified to support vertical connections among all eLessons in the course),

$\longleftarrow-$ redirection from the contents of the LO to another LO in any part of the course (any eLesson in the course),

\footnotetext{
- reminder of the contents of any other LO within the course.
}

The suggested extensions therefore provide not only means to create fixed learning paths through eLessons, but also to provide a variety of paths using all LOs from eLessons within the course and setting different conditions to be fulfilled by learners. Furthermore, the last two features offer a possibility to directly connect any part of one LO's contents to another LO within the same course - first one in order to redirect students' learning paths to other parts of eContent in order to, for instance, traverse to another eLesson in order to go through a part of the material presented in it; the second one in order to provide learners with pop-up reminders of the content of specific LOs, giving them timely hints when needed.

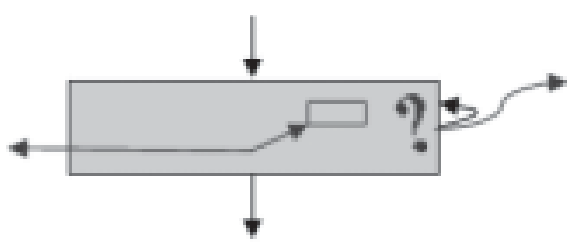

Fig. 1. Improved basic learning object. 
LOs, as self-standing, discrete pieces of instructional content that meet certain learning objectives, developed in this way can be arbitrary combined while planning eLessons. Using the best practice guide issued by Carnegie Mellon University (Carnegie Mellon University, 2003) is most appropriate for these purposes. This guide provides instructional designers with useful guidelines for identifying and designing LOs, structuring tests, navigating, sequencing and packaging the content. Sequencing, the most complex issue it deals with, prescribes the manner in which students receive individual pieces of content from the LMS, which controls the movement of the student from LO to LO with inter-LO sequencing. Therefore, the LMS essentially performs all of the branching of the content based upon behaviours defined by the designer and input by a programmer. This allows a set of LOs to be sequenced in many different ways, depending upon the designer who structures the content and the student to whom the content will be delivered.

A rather complex example of an eLesson sequence diagram is presented in Fig. 2. It is based on some of the sequencing templates proposed by Carnegie Mellon University (CMU) and having in mind our extensions of Moodle's Lesson module which enabled us to use of the templates. CMU templates are generally used to describe potential behaviours of LOs according to various instructional design strategies. While developing truly adaptive eLessons the instructional designers should explore sequencing possibilities suggested in complex templates (5-10) and possibly go beyond that.

The aforementioned and other developed extensions, like conditional jumps and possibility to include pre- and post-tests in eLessons, were therefore necessary for us to trace student progression, as well as to connect and combine LOs according to the CMU templates. Possibilities of their use in a hypothetical eLesson are illustrated in Fig. 2 and further explored in the rest of this section.

The lesson branches at the very beginning so the student can choose one of the subtopics to explore. Besides explanations of certain concepts, subtopics contain assessment LOs. Additional branching is available in some of the subtopics - direct links from the text of the introductory LO and some other LOs to specific parts of the current or other lessons in the course are offered. Pale aggregations and LOs are used to suggest that LOs from other lessons are used. Pre-test and post-test are distincted by the stated objectives connected to LOs which offer the appropriate information to fulfil them.

\subsection{Interconnection Between LOs}

One of the most useful newly developed features is the possibility to directly connect any part of one LO's contents to another LO (Komlenov et al., 2008). There are at least two excellent functionalities of such an extension: redirection of students' learning paths to other parts of eContent and simple reminders.

These functionalities could be rather valuable if used moderately, especially for eLessons that are not graded, as teachers sometimes want to allow their students to wander through eLessons in several different ways. They can now provide several possible learning paths and supply their students with various meaningful links from each LO to the others. 


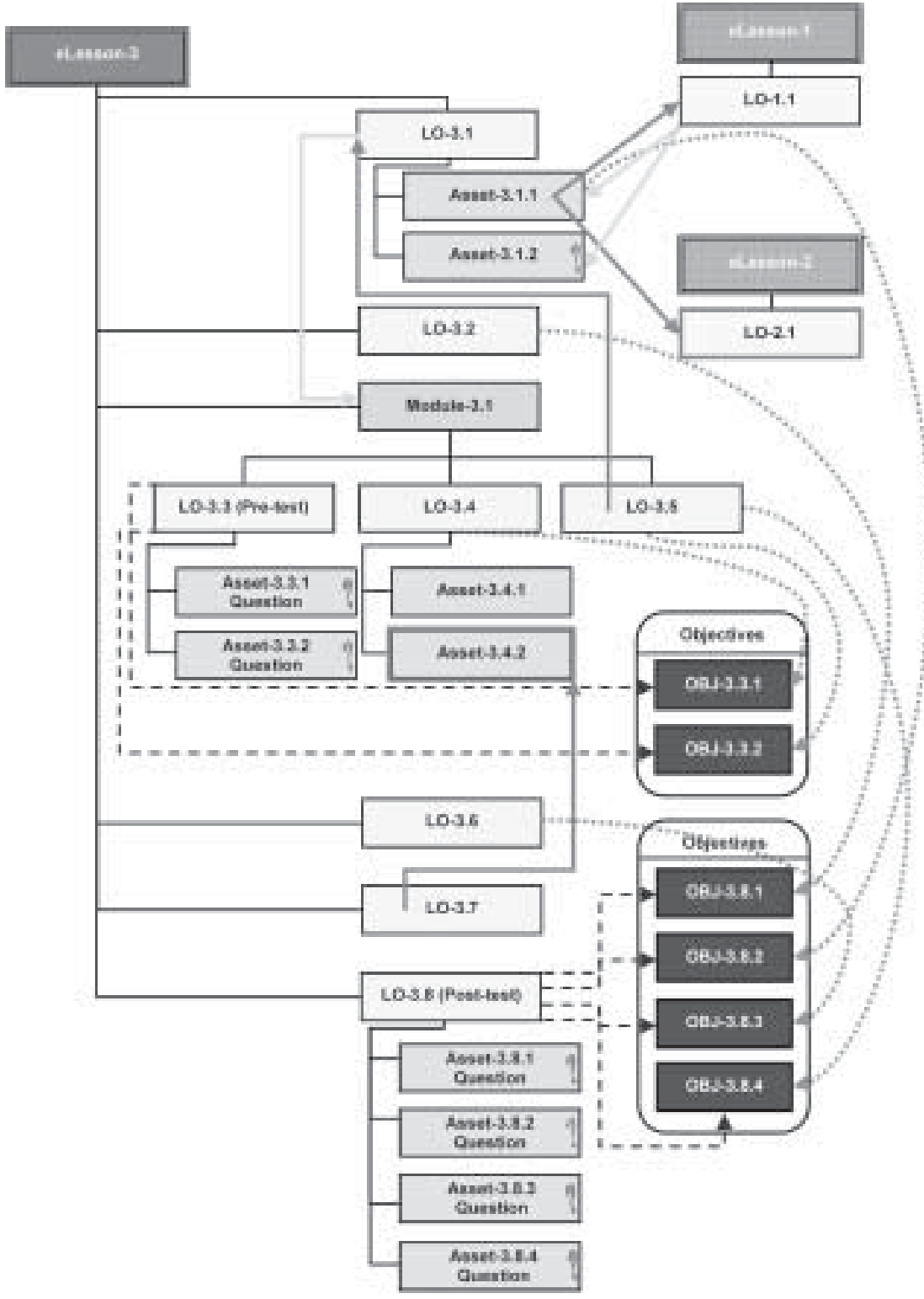

Fig. 2. eLesson sequence diagram - an example.

Apart from complete redirection of students' learning paths, there is a possibility to just remind them of the contents of certain LOs. In fact, it is often useful to make it feasible to students to briefly access information from other LOs, even from different eLessons within the same course, but afterwards simply move on through the lesson. This provides the instructional designers with an opportunity to reuse the existing material without duplicating it. 
This can be a suitable way to make additional information available to students as they mouse over hot spots on the screen, relevant bits and pieces of information are revealed. The students then interact with them in the preferred sequence.

\subsection{Extended Jumps}

Further updates of the extension presented in Section 4.1. led to the enriched choice of target pages that can be referenced from any LO (Komlenov et al., 2008). Now all LOs from eLessons belonging to the current eCourse are available as target LOs.

Another version of extended jumps is realized through slight changes in Lesson module. It offers course designers the possibility to create Jump-to links, as links that students follow after studying a LO and possibly answering a question, to LOs from any eLesson that belongs to the eCourse. Previously they could link only to the parts of the same eLesson (Fig. 3).

This new feature can be particularly useful in terms of content reusability and flexibility of learning paths. In fact, questions or probes sprinkled throughout an eLesson can be used to do more than simply return the student to the last few screens of content for another review (Driscoll and Carliner, 2005). Some answers could lead to additional explanations, others to skipping some parts of the lesson that the student is already familiar with. All this unquestionably causes production of additional material - explanations, background etc. or connecting the current contents with LOs from other eLessons.

\subsection{Conditional Jumps}

Analyzing students' learning paths and directing them further through the eContent according to their progress in the most appropriate and meaningful way is certainly the

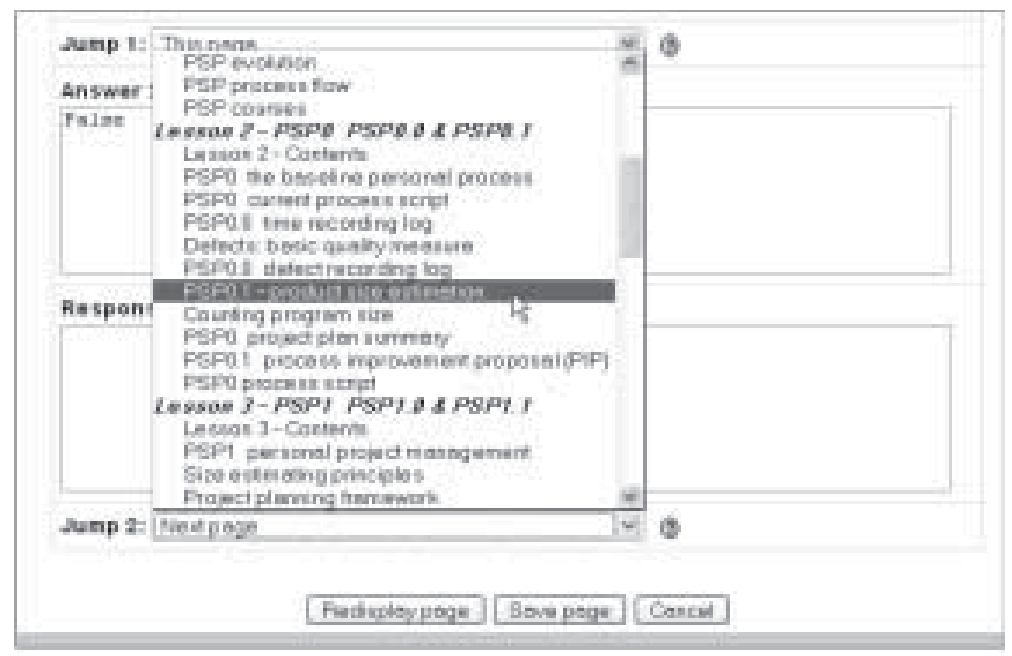

Fig. 3. Extended jump. 
ultimate approach when creating an adaptive eLesson. Therefore, the authors have extensively redesigned Moodle's Lesson module in order to provide the possibility of advanced branching with conditional jumps created at the time of lesson development, i.e., by teachers/instructional designers.

New features have been fully incorporated into standard Moodle's options in order to make their acceptance by experienced course developers rather quick and subtle. While regularly adding/editing their lesson pages and setting up links between them, now they have an opportunity to further explore the variety of learning paths empowered by this extension. If the appropriate option is activated conditional jumps can be used: whenever a page is edited there is a possibility to put extra conditions on any of the Jump-to links (Fig. 4).

By choosing the link in unless coming from (arrow a) field the page creator ensures that, when viewing the lesson and following their own learning path, students will move to the next page according to the previously visited one (if it is the one specified here). Target page for those occasions should be defined in which leads to page (arrow b) option (Fig. 4). If students access the current page after visiting a page different from the one set in the above condition, they move to the page given in the regular Jump-to link. All links can be either relative or absolute.

If an appropriate value is entered in the text field shown beside the first condition, accompanied by the more condition(s) (arrow c) label (Fig. 4), it is possible to add an arbitrary number of additional conditions on the Jump-to link. The page should be redisplayed to specify their details.

From the student perspective nothing has obviously changed. Students follow the lessons in the usual way, answer the questions prepared for them, make choices at the

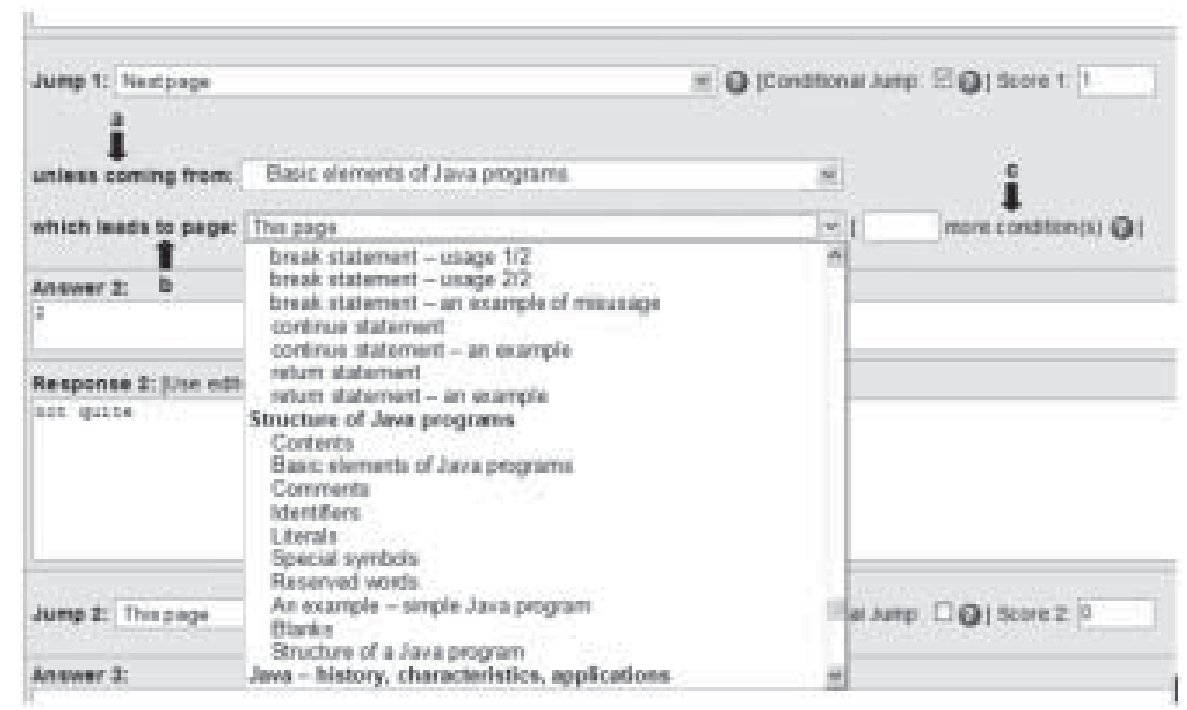

Fig. 4. Editing a conditional jump. 
branch tables, etc. but those activities are more carefully tracked and their learning paths are personalized in various ways.

\subsection{Pre- and Post-Tests}

Testing is an interaction that students have come to expect in the real as well as the virtual classroom. It can be a powerful tool in self-paced instruction (Driscoll and Carliner, 2005). If pre-tests are integral part of the proposed learning path, they are used to determine what section of the lesson students have already mastered and give them opportunity to skip those sections. Post-tests, on the other hand, can be very valuable to both students for tracking progression and teachers for judging the quality of learning material.

Moodle's Lesson module has an element called cluster that can be used for designing custom mini tests inside eLessons. A cluster represents a set of questions from which one or more may be randomly chosen. Clusters should be completed with an End of cluster (EOC) page for best results; otherwise they treat the End of lesson as the EOC. Questions within a cluster may either link to the EOC to exit the cluster, jump to an unseen question within the cluster, or to any other page in the lesson. This also enables the creation of learning scenarios with a random element.

Our decision to extend the cluster approach was motivated by the need to make creation of pre- and post-tests more straightforward and to provide remediation possibilities. Therefore, another step in extensive redesign of the Lesson module has been performed. Testing utility is now fully integrated into standard cluster functionality for its easier application.

In order to create a pre- or post-test one should create the desired number of questions (question pages) of any kind, and place them between a cluster page and end of cluster. After that some further editing of the cluster page and the end of cluster should be done. At the top of the cluster page option Adaptive Cluster Type (Fig. 5) should be checked, after which the desired test type must be chosen.

If a cluster is marked as a pre-/post-test, when the page is edited a possibility to define remediation pages for all questions within the cluster is offered (Fig. 6).

In order to make sure that a pre- or post-test will work properly, the instructional designer should set all the jumps within the cluster to Next page or Unseen question within a cluster (arrow a), according to whether the questions are to be displayed to the students in the specified order or shuffled. The latter provides for more adaptivity when repeating the tests - only failed questions are redisplayed.

Finally, at the page marking the end of cluster, two jump-to links must be defined:

- Continue Jump, which leads to the page students will see after the test ends as the default continuation of the learning path;

- Skip Jump for a pre-test, which leads to the page students will see after they successfully solve the test as the beginning of their personalized continuation of the learning path; or instead a jump-to link called Return Jump for a post-test, leading to the page students should see as a starting point for repeating the lesson (or its part covered by the test), for instance after they fail the test. 


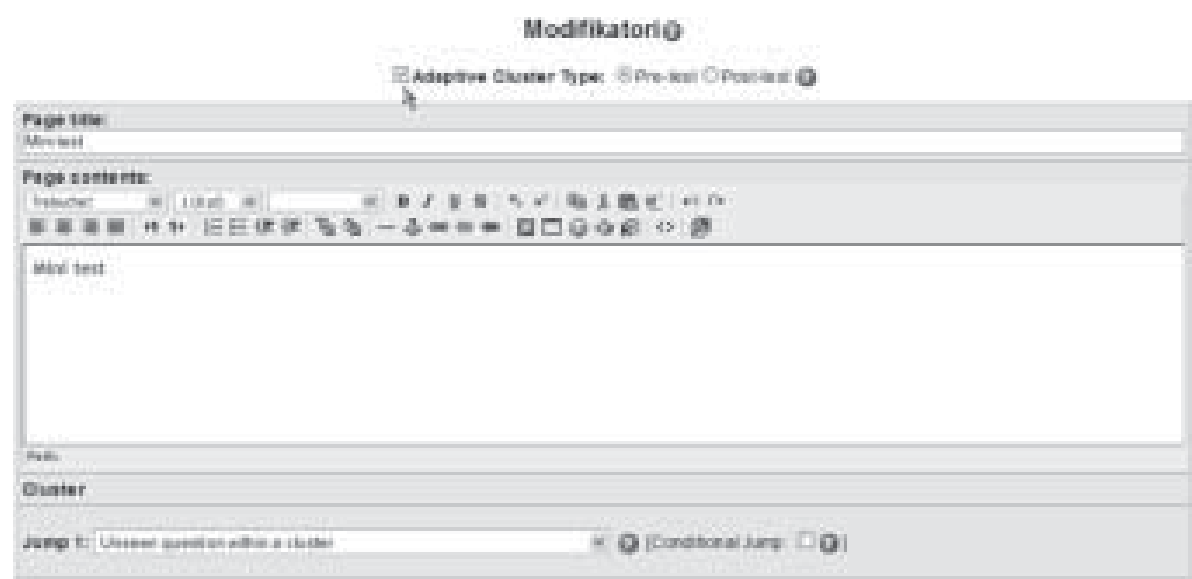

Fig. 5. Editing the beginning of a pre-/post-test.

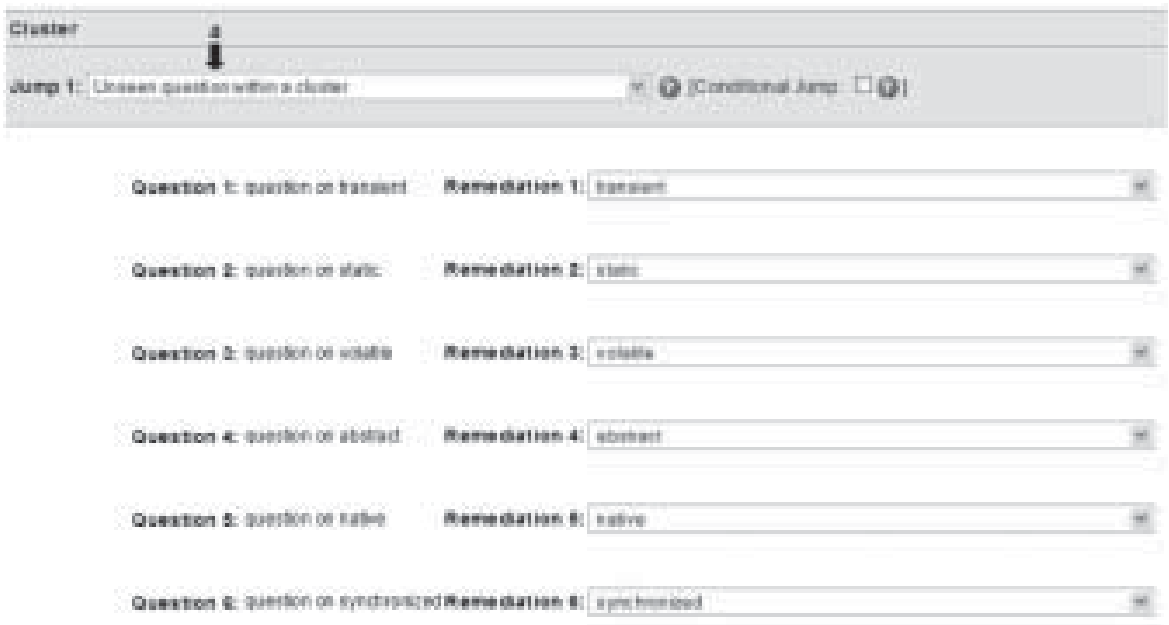

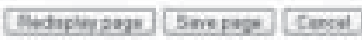

Fig. 6. Defining remediation pages.

When students reach the end of such a cluster their answers are analyzed and the appropriate continuations of the learning paths are offered according to these settings and their results (Fig. 7).

If a student answers correctly less then half of the questions in a test it is strongly advised that the whole lesson (or its section) is visited (again). The student enters the following (part of the) lesson in case of a pre-test has previously been completed, or is by default returned to the previous section that was not mastered, after finishing a post-test.

In situations when students answer correctly between 50\% and 90\% of the posed questions, they are advised to follow remediation links and after fulfilling the knowledge 


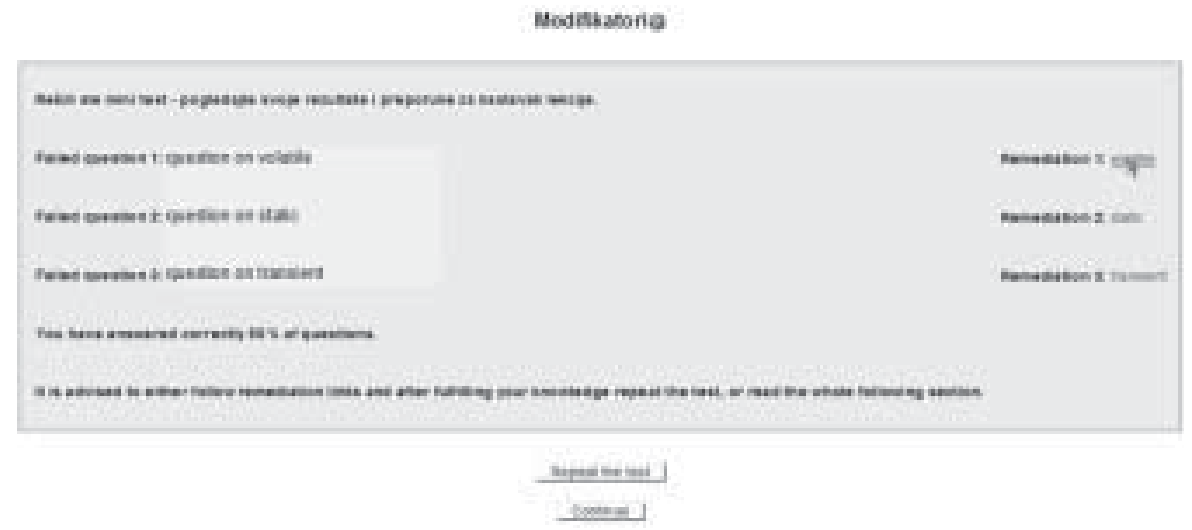

Fig. 7. Remediation links displayed after the test.

to repeat the test, or simply to read the whole section (again, for post-tests).

Remediation links lead to lesson pages (shown in pop-up windows) with explanations that can help students gather bits of knowledge needed to successfully answer failed questions.

Students who decide to repeat the test, preferably after (re)reading some of the pages following the remediation links, get another chance to:

- collect enough correct answers to qualify for skipping the (part of the) lesson covered by the pre-test;

- continue to the next segment of the lesson after repeating the post-test.

Students thus, while going through an eLesson, enter specialized clusters of questions, provide answers, receive feedback, further explanations, and personalized pieces of advice on how to continue their learning paths. If an eLesson is organized in such a way it offers students an opportunity to explore its contents at their own pace, according to their previous knowledge and preferred way of learning.

\section{Conclusions}

Proper systems with adaptive functionalities can be of great help to students since they help them navigate through a course by providing user-specific, not necessarily linear paths (Hauger and Köck, 2007). We have therefore extended one of the most popular and widely used LMSs, Moodle, focusing on its Lesson module in order to make it more adaptive and flexible.

Simple adaptability is enabled by the possibilities to directly connect contents of different assets, vertically bond LOs from different contexts, trace students' advancement and modify their learning paths, as well as by sequencing in a pre-test $=>$ study $=>$ posttest structured activities. Students therefore progress through eLessons along paths determined by the designer or by their own choices. 
Such a system presents a good basis for the use of artificial intelligence techniques and the implementation of a solution enriched with functionalities for more advanced adaptability. Current solution is based on well-known theoretical postulates, as well as needs emerged in contemporary practice. Its special strength is recognized in user-friendly implementation which makes the development of (semi-) adaptive eLessons quite straightforward, using a somewhat upgraded regular LMS.

Starting from the new school year the developed system will be applied in most of the Computer Science courses at our Department. A thorough analysis of student achievements will be performed to observe whether methods applied to adapt the learning experience to the needs and capabilities of every student indeed produce higher overall grades and more persistent knowledge.

Our current research in the field of cognitive science might eventually lead to creation of a completely adaptive eLearning environment. Special attention will be paid to exploring students' preferred learning styles by testing, activity tracking and using various data mining techniques.

Acknowledgments. This work was supported by the Serbian Ministry of Science and Technological Development within the project "Abstract Methods and Applications in Computer Science" (No. 144017A).

\section{References}

Ahmed, O. (2005). Migrating from Proprietary to Open Source Learning Content Management Systems. Department of Systems and Computer Engineering, Carleton University, Ottawa.

Bergsträßer, S., Zimmermann, B., Rensing, C., Steinmetz, R. (2007). Building a representation of learning resources to support their re-purposing. In: Montgomerie, C., Seale, J. (Eds.), World Conference on Educational Multimedia, Hypermedia and Telecommunications, Vancouver, Canada, pp. 3128-3136.

Bothe, K., Budimac, Z., Cortazar, R., Ivanovic, M., Zedan, H. (2009). Development of a modern curriculum in software engineering at master level across countries. Computer Science and Information Systems, 6(1), $1-21$.

Budimac, Z., Ivanovic, M. (1992). On specialized language for information (re)prezentation. In: First International DECUS at-Large Symposium on Computer and Information Sciences - Latest Trends in Computing. Antalya, Turkey, pp. 175-187.

Budimac, Z., Putnik, Z., Ivanovic, M., Bothe, K., Schützler, K. (2009). On the assessment and self-assessment in a students teamwork based course on software engineering. Computer Applications in Engineering Education (in print).

Carnegie Mellon University (2003). SCORM Best Practices Guide for Content Developers. 1st Edition, Learning Systems Architecture Lab, CMU, Pittsburgh.

De Bra, P., Aerts, A., Berden, B., De Lange, B., Rousseau, B., Santic, T., Smits, D., Stash, N. (2003). AHA! The adaptive hypermedia architecture. In: 14th ACM Conference on Hypertext and Hypermedia. Nottingham, UK, pp. 81-84.

Di Domenico, F., Panizzi, E., Sterbini, A., Temperini, M. (2005). Analysis of Commercial and Experimental ELearning Systems. Quality, Interoperability and Standards in E-Learning Team. TISIP Research Foundation, Trondheim.

Driscoll, M., Carliner, S. (2005). Advanced Web-Based Training Strategies - Unlocking Instructionally Sound Online Learning. Pfeiffer, John Wiley \& Sons.

Fink, J., Kobsa, A., Schreck, J. (1997). Personalized hypermedia information provision through adaptive and adaptable system features: user modeling, privacy and security issues. In: Workshop Adaptive Systems and 
User Modeling, World Wide Web of the 6th Int. Conference on User Modeling. Chia Laguna, Sardinia, Italy, pp. 456-467.

Georgouli, K., Skalkidis, I., Guerreiro, P. (2008). A framework for adopting LMS to introduce e-learning in a traditional course. Educational Technology \& Society, 11(2), 227-240.

Graf, S., List, B. (2005). An evaluation of open source e-learning platforms stressing adaptation issues. In: 5th IEEE Int. Conference on Advanced Learning Technologies. IEEE Press, pp. 163-165.

Graf, S. (2007). Adaptivity in Learning Management Systems Focussing on Learning Styles. PhD Thesis. Faculty of Informatics, Vienna University of Technology.

Grigoriadou, M., Papanikolaou, K., Kornilakis, H., Magoulas, G. (2001). INSPIRE: An intelligent system for personalized instruction in a remote environment. In: $3 r d$ Workshop on Adaptive Hypertext and Hypermedia. Sonthofen, Germany, pp. 13-24.

Hauger, D., Köck, M. (2007). State of the art of adaptivity in e-learning platforms. In: 15th Workshop on Adaptivity and User Modeling in Interactive Systems, held in the context of Lernen-WissensentdeckungAdaptivität 2007 (LWA 2007). University of Hildesheim, Hildesheim, Germany, pp. 355-360.

Hockemeyer, C., Conlan, O., Wade, V., Albert, D. (2003). Applying competence prerequisite structures for e-learning and skill management. Journal of Universal Computer Science, 9(12), 1428-1436.

Hoic-Bozic, N., Mornar, V. (2005). AHyCo: A Web-based adaptive hypermedia courseware system. Journal of Computing and Information Technology, 13(3), 165-176.

IEEE P1484.12.1-2002 (2002). Draft Standard for Learning Object Metadata, IEEE, Inc.

Ivanovic, M., Budimac, Z. (1992). Less - an authoring object oriented programming language. In: 17th Int. Summer School with Conference - Information Technologies and Programming. Sofia, pp. 77-82.

JMCSE, Joint MSc Curriculum in Software Engineering. Project supported by Tempus under the grant no. CD-JEP-18035-2003, 2004-2007. http: / / perun.pmf .uns.ac.rs/msc-se/

Komlenov, Z., Budimac, Z., Ivanovic, M. (2008). Introducing adaptivity to e-lessons to enhance student learning. In: 7th European Conference on e-Learning. Agia Napa, Cyprus, pp. 571-580.

Kostolányová, K., Šarmanová, J., Kapounová, J., Takacs, O. (2009). Personalisation of learning. In: $m$ ICTE2009 Conference on Research, Reflections and Innovations in Integrating ICT in Education. Lisbon, Portugal, pp. 234-237.

Munoz, K., Van Duzer, J. (2005). Blackboard vs. Moodle: A Comparison of Satisfaction with Online Teaching and Learning Tools. Humboldt State University.

Portela Núñez, J.M., Huerta Gómez de Merodio, M.M., Pastor Fernandez, A. (2009). How to find the best solution to a problem using a LMS. In: m-ICTE2009 Conference on Research, Reflections and Innovations in Integrating ICT in Education. Lisbon, Portugal, pp. 1320-1322.

Rice, H.W. IV (2006). Moodle: E-Learning Course Development - A Complete Guide to Successful Learning Using Moodle. Packt Publishing.

Sauerstein, G. (2007). KI-Ansätze zur Lerneradaption in Lern-Management-Systemen. Diplomarbeit, Institut für Technische Informatik und Ingenieurinformatik, Fakultät für Informatik und Automatisierung, Technische Universität Ilmenau (in German).

SE-CSERC. Software Engineering: Computer Science Education and Research Cooperation. DAAD supported project, 2001-2009. http: / /www2 . informatik. hu-berlin. de/swt/intkoop/daad/

Stewart, B., Briton, D., Gismondi, M., Heller, B., Kennepohl, D., McGreal, R., Nelson, C. (2007). Choosing MooDLe: An evaluation of learning management systems at Athabasca University. International Journal of Distance Education Technologies, 5(3), 1-7.

Süß, C., Kammerl, R., Freitag, B. (2000). A teachware management framework for multiple teaching strategies. In: World Conference on Educational Multimedia, Hypermedia and Telecommunications. Montreal, Canada, pp. 1101-1106.

Tiarnaigh, M. (2005). Adaptive Moodle: An Integration of Moodle (Modular Object-Oriented Dynamic Learning Environment) with an AHS (Adaptive Hypermedia System). Centre for Computing and Language Studies, Trinity College, The University of Dublin.

Weber, G., Brusilovsky, P. (2001). ELM-ART: An adaptive versatile system for Web-based instruction. International Journal of Artificial Intelligence in Education, 12, 351-384. 
Z. Komlenov is a PhD student and a research and teaching assistant at the Department of Mathematics and Informatics, Faculty of Science, University of Novi Sad, Serbia. Her research interests include learning technologies, application of intelligent techniques, software engineering, programming languages and tools. She is a researcher in several international projects and author or co-author of 8 research papers.

Z. Budimac holds the position of a full professor and is affiliated with the Department of Mathematics and Informatics, Faculty of Science, University of Novi Sad, Serbia. His current research interests are in software engineering, mobile agent systems and eLearning. He is a researcher and principal investigator in several international projects and author or co-author of more than 180 papers and 14 books.

M. Ivanovic holds the position of a full professor and is affiliated with the Department of Mathematics and Informatics, Faculty of Science, University of Novi Sad, Serbia. Her research interests are in software agents, data mining, case-based reasoning, learning technologies and software engineering. She is a researcher and principal investigator in several international projects and author or co-author of more than 190 papers and 11 books. She is also Editor-in-Chief of the Computer Science and Information Systems Journal (ComSIS). 


\title{
Mokymosi valdymo sistemos adaptyvumo savybės išplèstinėms elektroninèms pamokoms kurti
}

\author{
Zivana KOMLENOV, Zoran BUDIMAC, Mirjana IVANOVIC
}

Kiekvienas mokinys mokykloje igyja skirtingu tam tikru pradiniu žinių, kiekvienas mokinys pasižymi skirtingomis savybėmis bei mokymosi stiliais. Siekiant pagerinti mokiniu mokymosi procesą, internetiniai kursai turètų turèti tam tikrą adaptyvumo lygi. Virtualiosiose mokymosi aplinkose, kurios pasižymi tokio pobūdžio funkcijomis, mokiniai gali tiksliai pasirinkti medžiagos turinio nagrinèjimo eiliškumą arba gali būti nukreipti link reikiamos mokymo medžiagos atsižvelgiant i jų naujų žinių igijimo pažangą. Straipsnyje pateikiamas tokios mokymosi aplinkos igyvendinimas: išplečiant atvirojo kodo mokymosi valdymo sistemą "Moodle". 